\title{
Sphenomaxillary Fossa
}

National Cancer Institute

\section{Source}

National Cancer Institute. Sphenomaxillary Fossa. NCI Thesaurus. Code C33584.

A small, pyramidal space located between the pterygoid process, the maxilla, and the palatine bone. 